\title{
Responding to Health Disparities in Behavioral Weight Loss Interventions and COVID-19 in Black Adults: Recommendations for Health Equity
}

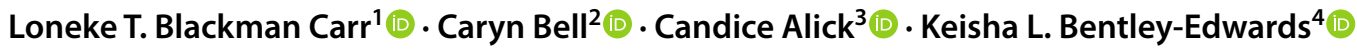

Received: 22 October 2021 / Revised: 15 February 2022 / Accepted: 16 February 2022 / Published online: 22 February 2022

(c) W. Montague Cobb-NMA Health Institute 2022

\begin{abstract}
COVID-19 has disproportionately impacted Black adults with high prevalence and mortality rates. Obesity is a central factor in the severity of COVID-19 and related treatment. Behavioral weight loss interventions are an efficacious treatment for obesity, but consistently, Black men and women are minimally represented, and weight loss outcomes are less than clinically significant thresholds. This commentary draws parallels between COVID-19 racial disparities, disparate obesity rates, weight loss treatment outcomes, and underlying systemic racial context. This paper also indicates paths forward to address racialized societal norms in obesity treatment to advance health equity in obesity and reduce acute disease vulnerability. Recommendations for behavioral medicine practice and policy include (1) expanding the research lens to prioritize Black scholars and institutions to generate innovative research questions, (2) creating trustworthy relationships with Black community members to bolster recruitment and retention, (3) employing qualitative methods to facilitate better intervention design and uncover influences of racialized social context, (4) centering Black adults in weight loss interventions, and (5) using multilevel approaches that integrate policy into interventions. Moving forward, this commentary aims to make plain the multilayered form and function of racism, its impact on COVID-19 and obesity, and offer pathways to improve behavioral weight loss interventions that can produce more equitable outcomes.
\end{abstract}

Keywords Obesity $\cdot$ COVID-19 $\cdot$ Structural racism $\cdot$ Weight loss

\section{Background}

As of February 2022, over seventy-six million cases of the novel coronavirus 2019 (COVID-19) have been reported in the USA, and deaths are now above 900,000 according to the Centers for Disease Control and Prevention [1]. In the early period of the pandemic, it levied an uneven tax on

Loneke T. Blackman Carr

Loneke.blackman_carr@uconn.edu

1 Department of Nutritional Sciences, College of Agriculture, Health, and Natural Resources, University of Connecticut, 27 Manter Road, Unit 4017, Storrs, CT 06269, USA

2 Department of Global Community Health and Behavioral Sciences, Tulane University, New Orleans, LA, USA

3 Department of Human Sciences, North Carolina Central University, Durham, NC, USA

4 Samuel DuBois Cook Center On Social Equity, School of Medicine, Duke University, Durham, NC, USA
Black adults across the USA, and examples of this inequity were replicated around the nation. In Louisiana, Black adults comprised nearly $54 \%$ of COVID-19 deaths [2], while representing only $33 \%$ of the state's population [3]. The disproportionate burden was seen in Michigan, where Black people, who made up $14 \%$ of the population, yet experienced $23 \%$ of the state's deaths [4-6]. In New York City, an early epicenter of the pandemic, Black adults accounted for almost double the number of COVID deaths compared to their white counterparts [7].

Obesity has been identified as a factor that impacts the severity of COVID-19 and its treatment [8]. The functional capacities of the pulmonary system are decreased in individuals with obesity, especially those with severe obesity [9]. Simonnet et al. found that the proportion of hospitalized patients who required ventilation increased directly with body mass index (BMI), and was most pronounced in those with a BMI $>35 \mathrm{~kg} / \mathrm{m}^{2}$ [10]. Furthermore, independent of age and the comorbidities of diabetes and hypertension, the need for ventilation was associated with 
patients having a BMI $>35 \mathrm{~kg} / \mathrm{m}^{2}$ [10]. A retrospective investigation of Intensive Care Unit admissions and ventilator use, both indicators of COVID-19 severity, revealed a positive association with a BMI $>35 \mathrm{~kg} / \mathrm{m}^{2}$ when controlling for comorbidities [11]. Thus, obesity, particularly severe obesity, increase the severity of COVID-19, which is especially problematic for communities most affected by obesity like Black adults. While just over $40 \%$ of the general adult population lives with obesity (BMI $\geq 30 \mathrm{~kg}$ / $\mathrm{m}^{2}$ ), Black adults have a disproportionate burden of about $50 \%$ [12]. More granularly, through the intersectional lens of race and gender, nearly $60 \%$ of Black women live with obesity, greater than all other groups [12]. Just over $40 \%$ of Black men live with obesity [12]. Severe obesity $\left(\mathrm{BMI} \geq 40 \mathrm{~kg} / \mathrm{m}^{2}\right)$ is also highest in Black adults [12], and is projected to become the most common BMI category in this demographic [13]. Projections of obesity and severe obesity rates indicate that this disproportionately distributed health burden will worsen over the next decade [13]. There is an urgent present and future need to address weight in meaningful and effective ways.

Behavioral weight loss interventions (BWI), characterized by dietary and physical activity modification plus behavior change strategies, are an efficacious obesity treatment, but less so for Black adults [14]. Seminal multicenter trials like the Diabetes Prevention Program, Look AHEAD, and PREMIER demonstrate the efficacy of this approach [15-17]. However, racial disparities reflect insufficient recruitment and retention [18], inadequate reporting of outcomes by race [19], and subpar weight loss outcomes in Black adults - a consistent thread in these trials [16, 17, 19-21]. This begets an important question for the acute and long-term health of Black adults. Why do obesity and disparate BWI outcomes persist?

Similar to obesity, COVID-19 has disproportionately impacted Black communities in the USA. However, largely absent from COVID-19 discourse are the similarities between the underlying structures that made the ground ripe for its acute impact. Racial inequities in structural factors like racial segregation, housing, and occupational characteristics contribute to disproportionate exposure to the virus. Discrimination in healthcare, medical mistrust, and racial inequities in health outcomes like obesity also contribute to racial inequities in COVID-19 related mortality [22-25]. Black race is not an explanatory factor in COVID-19 and obesity disparities. Rather, it is racialized structures and systems that facilitate the undue high burden of poor health. In this commentary, we discuss systematic racism and how it may perpetuate obesity and COVID-19 severity in Black adults as a means to understand persistent disparities and inform future behavioral weight control interventions.

\section{Challenges to Addressing Obesity in Black Adults}

\section{Racism and Obesity}

A large literature on racial disparities in obesity has focused on individual-level factors like race differences in behaviors, body size preferences and perceptions, and socioeconomic status (SES). However, these factors do not explain the persistent racial disparities in obesity between Black and White adults [26, 27]. Racism is a fundamental cause of health inequities [28], and studies have demonstrated that racism is linked to obesity and related behaviors including diet and physical activity [29-36]. Black men and women who report experiencing racial discrimination have higher BMI [33, 36-38], and discrimination predicts the incidence of obesity and weight gain in Black women [32]. Experiencing discrimination can also have implications for obesity-related behaviors [34, 35, 39-41]. Studies show that discrimination is associated with obesogenic dietary behaviors among Black women and men $[34,35,39,42]$, and worry about discrimination or racial vigilance has been cited as a barrier to physical activity among Black men [41]. Racial vigilance has also been associated with higher odds of obesity in Black Americans [31] and larger waist circumference among Black women [30]. Behavioral weight loss interventions (BWI) must account for the role of discrimination and racial vigilance in dietary and physical activity behaviors among Black women and men.

Though these studies demonstrate that racial discrimination contributes to higher rates of obesity among Black adults [29-36], racism in the USA extends far beyond individual-level experiences of discrimination. Structural racism is defined as "the macrolevel systems, social forces, institutions, ideologies, and processes that interact with one another to generate and reinforce inequities among racial and ethnic groups" [43], and scholars have linked race disparities in obesity to structural racism by describing how it shapes racial differences in the social determinants of health related to obesity outcomes and behaviors. For example, a history of discriminatory practices and policies among federal-, state-, and local-level institutions like the Federal Housing Authority, banks, and real estate agents have resulted in racial segregation in US cities [43-45] such that Black urban residents are more likely to live in food environments with less access to healthy food options [46] and a preponderance of unhealthy food options like fast food restaurants [47, 48]. Racial segregation has been positively associated with obesity [33, 49-56], dietary behaviors [53], and physical activity [57-59]. Studies have also linked other manifestations 
of structural racism to obesity. Racial inequities at the state- and county-level have been considered markers of structural racism [60], and studies indicate that counties with more racial inequity in poverty, unemployment, and homeownership had higher rates of obesity [29]. Another manifestation of structural racism is the mass incarceration of Black men in the USA and experiences of police brutality [44]. Recent studies demonstrate that living in a neighborhood with increased police violence is associated with higher obesity rates [61], particularly among women [62].

Structural factors are also implicated in racial inequities in COVID-19 incidence and mortality. The Expanded Obesity Research Paradigm and the National Institute on Minority Health and Health Disparities Research Framework provide a multilevel conceptualization of the social underpinnings of racial disparities in obesity and other health outcomes like COVID-19 [63, 64]. Data from the city of Philadelphia shows that COVID-19 cases are highest in the most segregated neighborhoods [65]. Moreover, scholars suggest that the key drivers of racial inequities in COVID19 include other manifestations of structural racism such as restrictions in employment opportunities [44], reflected in overrepresentations in low-wage, and public-facing service jobs [66-68]. Though there are variations in the specific structural determinants associated with each, racial inequities in obesity and COVID-19 incidence and mortality are rooted in structural racism. While race may be perceived as a biologic reason for health disparities, the concept of biological race is unfounded in scholarly literature $[69,70]$. Rather, race is purely a social structure intertwined with other social structures in the American context. The form and function of racism, not race itself, is a key in obesity's racial disparities.

\section{Persistent Racial Disparities in Obesity Treatment}

While the success of behavioral weight loss interventions is generally apparent, so are the issues concerning Black men and women. Standard BWI are efficacious, typically producing 5-10\% weight loss, known to confer health benefits [15-17]. Yet, for Black women, BWI often produce small to modest weight loss, often below the $5-10 \%$ goal $[19,71]$. Black men may reach that goal, but weight losses observed in seminal trials demonstrate lower weight loss (approximately 2\% less) than their White male counterparts [72]. Sufficiently engaging Black men and women, who represent $12.4 \%$ of the US population [73], in BWI may inform next steps to improving weight loss outcomes. While representation of Black women has been observed, Black men's participation rates are lower [16, 20, 72]. In the DPP, Black men represented $5.7 \%$ of the study sample, while Black women represented $11.7 \%$ [20]. A similar trend is seen in other landmark, randomized controlled trials such as Look AHEAD (Black men: 9.1\%, Black women: 20.1\%) and the
Weight Loss Maintenance Trial (Black men: 11.6\%, Black women: $32.0 \%$ ) [72, 74]. In such trials, where samples are predominantly female and White, the Black-White disparity in weight loss outcomes remains, consistently demonstrating insufficient weight loss among Black women [17, 19, 71, 75, 76], and lower weight loss between Black and White men $[20,72]$. This can impact clinical indicators such as blood pressure, that when elevated over time progresses to hypertension. Differences in weight loss and low representation rates among men contribute to disparities in the development of obesity-related conditions - diabetes, heart disease, and other cardiovascular maladies among Black men who present with the highest mortality rates for such illnesses despite Black women having the highest rates of obesity [77].

Varied behavioral engagement during BWI may inform the racial gap in weight loss outcomes. Racial differences in self-reported physical activity in BWI have been mixed, indicating the presence of or no differences across the literature $[16,75,76]$. However, objectively assessed physical activity in BWI has shown greater amounts of engagement from baseline to study end in White versus Black adults [75]. Dietary outcome comparisons have been similarly mixed across racial and gender groups $[16,75,76]$, possibly owing to the self-report nature of dietary assessment. Adherence to various aspects of BWI engagement also reveal racial differences. Greater BWI session attendance, in-person or online, has been observed in White versus Black participants [21, 76]. More intervention contacts and submission of self-monitoring logs have also been seen in non-Black or White compared to Black subjects in BWI $[21,75]$. The consistent challenge to produce meaningful individual-level engagement highlights these variables as important targets to maximize treatment effectiveness. What remains largely absent from the literature base is connection of the individual-level behaviors and outcomes to societal variables, so that investigators may better understand the impeding or supportive mechanisms, and proceed knowledgeably. Factors contributing to these disparities reach beyond individual-level determinants and interpersonal racism. Obesity incidence is impacted by structural racism affecting Black men and women, and is therefore embedded in their obesity treatment experience and outcomes. Though researchers are now emphasizing the importance of frameworks that consider higher levels of influence on individual behaviors, attempts to address or effect change are often more difficult and require more resources, time, and a foundational acknowledgement of their existence.

Centering weight loss treatment on Black adults is necessary to consider their unique behavioral contexts. BWI study samples predominantly include White women, and thus have been designed for this demographic, largely developed by non-Black researchers. Consequently, investigating 
and integrating factors in weight loss among Black men and women that may uniquely and tremendously impact treatment efforts remains understudied. Such factors may include food insecurity and poverty, where Black communities have a greater burden of both compared to the general population [78]. This is reflected in the high participation rate of mostly woman-led Black households (41.6\%) in government assistance programs like the Supplemental Nutrition Assistance Program (SNAP), Medicaid and Temporary Assistance for Needy Families [79]. A 5\% increase in the odds of being very low food secure, after adjusting for socioeconomic and demographic confounders, results from a one-unit increase in the frequency of lifetime racial discrimination [80]. Experiencing a racialized social environment can conflict with behavior change strategies and recommendations inherent in BWI. Prioritizing health has even led to tragedy among Black men, as illustrated by the murder of Ahmaud Arbery, who was shot while jogging by three White men [81]. Black men are less likely to engage in physical activity in mostly White neighborhoods compared to more diverse or predominantly Black neighborhoods, perhaps harkening to their survivalist social acumen of how they are perceived by others who may criminalize their presence [41]. Black women's activity shows an opposite relationship, as their activity increases as the Whiteness of a neighborhood does, likely due to the increased resources to be active [41]. There exists a gendered and racialized aspect to physical activity engagement that can be limiting, in its most benign form, and deadly in its most virulent. Failing to measure, address, or acknowledge these real contextual barriers in weight loss treatment likely contributes to the subpar engagement and outcomes produced in Black adults.

\section{Recommendations to Advance Obesity Treatment}

Centering the full context of the lives of Black adults is essential to making progress in obesity treatment. Forward movement in weight reduction likely hinges on understanding the myriad barriers and facilitators of weight loss among Black adults. Considering the social milieu discussed, daily needs for survival and thriving may supersede individual focus on weight status [82]. Key frameworks [63, 64] developed to guide how to improve minority health and obesity include the following elements: the experiences and insider knowledge of Black investigators and community members to generate novel research questions, incorporating the context of Black life through qualitative methods (e.g. ethnography, content analysis), sourcing expertise from various disciplines (e.g. sociology, literature, economics), and studying and incorporating the historical, physical, cultural, social, and physical contexts of health behaviors.
Furthermore, addressing obesity inequities requires consideration for cultural food preferences, the impact of food marketing, socioeconomic position, stress and coping strategies, cultural assets, social capital, and support [82]. Most importantly, BWI interventions should move beyond simply encouraging behavior change to addressing the structural factors that lead to high obesity rates among Black adults. This may involve multilevel approaches including policy change and other efforts to address upstream factors that create disparities and hamper weight loss interventions. We offer a set of recommendations in Table 1 to move the field towards progress for more inclusive weight loss treatment and equitable outcomes.

\section{Behavioral Medicine Practice}

\section{Broaden the Research Lens}

Reaching optimal weight outcomes among Black adults will require a shift in the approach to weight control. A foundational change can result from an increase in the number of and support for Black scholars committed to obesity research in Black adults. Researchers from this demographic will generate novel questions that may stem from shared lived experiences and social and cultural contexts [63]. Innovation through collaboration is made possible through diversity in knowledge [83]. In addition, the field must produce research that is relevant to Black adults. This can be achieved by addressing sociocultural factors in weight control research [63]. Perceived health risk and varied weight perceptions, for example, reflect social and cultural environments of Black adults. Interventions should be designed to incorporate and respond to these and other unique contextual factors.

Increasing the number of Historically Black Colleges and Universities (HBCUs) leading the charge in obesity research targeting Black adults may also broaden the scope of research. By providing access to higher education, and serving the broader social and political needs of the larger Black community, HBCUs are institutions valued in Black society and uniquely positioned to address historical barriers of institutional mistrust [84]. The importance of HBCUs is reflected in the production of Black scholars and clinicians. Nine of the top ten undergraduate institutions for Black PhDs in STEM fields are HBCUs [85], and previous studies have communicated the importance of HBCUs in the success of Black physicians [86]. Increasing the number of Black scholars who generate innovative research centering Black communities may be bolstered through HBCUs. By nature, HBCUs provide research environments that acknowledge structural racism and actively seek to dismantle its effects, which can impact the type and quality of research questions generated, recruitment/retention, and subsequent intervention design. 
Table 1 Recommendations for practice and policy

\begin{tabular}{|c|c|c|}
\hline Area of focus & Recommendation & Details \\
\hline \multirow[t]{3}{*}{ Behavioral medicine practice } & Broaden the research lens & $\begin{array}{l}\text { - Increase the number of and support for Black scholars investigating obe- } \\
\text { sity in Black adults } \\
\text { - Increase the number of Historically Black Colleges and Universities } \\
\text { (HBCUs) leading in obesity research targeting Black adults } \\
\text { - Address sociocultural factors in weight control research }\end{array}$ \\
\hline & Improve recruitment practices & $\begin{array}{l}\text { - Increase representation of Black adults beyond population metrics through } \\
\text { robust recruitment and retention } \\
\text { - Strengthen community ties through community-engaged and community- } \\
\text { based participatory research approaches }\end{array}$ \\
\hline & Expand and refocus methods & $\begin{array}{l}\text { - Employ various qualitative methods for intervention development } \\
\text { - Quantitatively examine the impact of structural racism (e.g. discrimina- } \\
\text { tion, negative police interactions, stress, wealth, poverty, food access, } \\
\text { neighborhood segregation) } \\
\text { - Power interventions to report findings by race and gender } \\
\text { - Center interventions on Black adults } \\
\text { - Prioritize communities with the greatest obesity burden } \\
\text { - Design interventions for those at medical risk (e.g. elevated HbA1c, } \\
\text { hypertension, abnormal blood lipids) }\end{array}$ \\
\hline \multirow[t]{2}{*}{ Policy-related directions } & Conduct multilevel interventions & $\begin{array}{l}\text { - Conduct multilevel interventions involving policy change in various con- } \\
\text { texts (e.g. church, work, local, state) }\end{array}$ \\
\hline & $\begin{array}{l}\text { Connect interventions to policy- } \\
\text { driven programs that alleviate } \\
\text { inequity }\end{array}$ & $\begin{array}{l}\text { - Engage Black adults already in poverty-alleviating programs (e.g. SNAP, } \\
\text { WIC) } \\
\text { - Increase engagement of Black men through poverty-focused programs }\end{array}$ \\
\hline
\end{tabular}

\section{Recruitment}

As previously illustrated, recruitment of Black adults into weight control interventions must remain a priority for investigators. Beyond matching population metrics, BWI should recruit and retain a sufficient number of Black adults to generate more broadly applicable findings. Increased representation of Black men and women within these studies will also allow for statistical analyses at the intersection of race and gender that may elucidate factors that can impact BWI effectiveness, such as weight stigma [87], and produce important information to guide future interventions. This is especially important given that obesity interventions are less effective among Black Americans [19].

Effective recruitment will also depend on the strength of community ties. The recruitment of underserved populations requires long-term relationship building and bidirectional transfer of benefits. Investigators must foster such relationships to establish trust with communities and to support intervention participation. Community-engaged and community-based participatory research approaches will be central to establishing trust and community collaboration [88].

\section{Methods}

Key ways to improve the relevance and effectiveness of BWI rests in the methods used. In this regard, simple steps may be taken. First, interventions may be powered to enable the reporting of findings by race and gender. This will inform recruitment needs. Investigators may also choose to focus on Black adults with medical risk, as success has been observed when engaging this group [71], and health improvement may be a more relevant reason to pursue lower weight. Importantly, to achieve progress in behavioral medicine practice for weight control is to center Black adults in the work [89, 90]. Making Black men and women the core of BWI recognizes the importance of addressing obesity disparities by prioritizing a community with a high prevalence of obesity. When Black adults are centered in this research, the factors involved in their weight status necessarily become centered as well. Thus, investigators may examine race- and gender-specific barriers, plus facilitators and motivators for weight loss pertinent to Black people. Reframing the need for weight loss and shifting the eligibility criteria to include other indicators such as waist circumference or percent body fat, leaning away from BMI as a main indicator of need may be important given lower body fatness at high BMI in Black compared to White adults [91], and the weak or non-existent relationship between BMI and mortality among Black adults $[92,93]$.

Centering Black men and women in weight loss treatment requires investigators to expand on what factors are examined and how. Applying quantitative methods to understand the impact of structural racism (e.g. discrimination, racial vigilance, wealth, segregation) on intervention outcomes will elucidate how the context of Black life plays a role in modifying weight status [29]. Underutilized qualitative methods become especially important to provide insight on 
the many factors that may influence weight status. These methods can be especially helpful when designing BWI, and provide an opportunity to complement quantitative findings while enriching the knowledge base on what may work for Black adults seeking weight loss.

\section{Policy Directions}

\section{Conduct Multilevel Interventions}

Individual-level obesity treatment approaches are impacted by higher-level factors. Ecological models illustrate the varying levels of influence and potential intervention from the central intrapersonal realm through the overarching policy level [94]. Health promotion interventions have largely addressed the individual level, with policy interventions receiving the least attention [94]. Multilevel interventions, where at least 2 levels of the ecological model are targeted [95], can initiate policy change in various contexts (church, work, local, state) while impacting other pertinent ecological levels. This offers a path towards potentially more successful interventions that may positively shift upper-level challenges to individual behavior change.

\section{Connect to Policy-Driven Programs Aimed at Inequity}

To address the economic hardship that may hinder Black adults seeking obesity treatment, BWI should connect to policy-backed poverty alleviating programs. Individuals engaged in pre-existing food-related (SNAP, WIC) and other financial assistance and stability programs are receiving support that may enhance their weight loss success. There is also a need to engage more Black men in SNAP and other poverty alleviating programs that support safe, secure housing, home ownership, and economic uplift to address the macrolevel manifestations of inequity [79]. These preexisting paths that aim to meet the needs of those with low income can reduce a major economic barrier to adopting the behavioral recommendations centered in BWI.

\section{Implications and Conclusions}

The racial differences observed in COVID-19 morbidity and mortality have magnified long-standing inequities that yield disparities across various health outcomes including obesity. Structural racism, manifested in segregation and obesogenic environments, greater poverty and unemployment, and other racialized differences in Black adults' lives propagate high obesity rates and impact dietary and physical activity behaviors. Improving the effectiveness of behavioral weight loss interventions is paramount to reduce obesity and thereby the risk of disease and death in Black men and women. To realize the full potential of behavioral weight loss interventions for Black adults, we must reimagine their design. This will require increasing the representation of Black men and women in BWI with sufficient power to assess contexts surrounding behavior changes and weight outcomes, measuring structural racism variables to assess the impact of Black life on weight loss, integrating qualitative methods to refine approaches and contextualize quantitative findings, developing meaningful community ties that emphasize a give and take nature to research to foster trust. Furthermore, we recommend policy be integrated through the conduct of multilevel weight loss interventions and connecting pre-existing policy-driven programs to approaches for obesity treatment. Doing so brings a socioecological approach to behavioral medicine that when absent may hamper intervention effectiveness. An intersectional lens framing the gendered experiences of Black men and women will also be essential to address health inequity and reduce the susceptibility to acute disease like COVID-19. A shift in scholarship to prioritize and be inclusive of a focus on Black life and health, including the structural nature of racism, is critical for progress in obesity treatment.

Author Contribution All authors made contributions to the conception and writing of this work. All authors approve this manuscript for publication.

Data availability No data was analyzed for this manuscript.

Code Availability No code is available given the nature of this article as a perspectives submission that did not include data analysis.

\section{Declarations}

Ethics Approval No human participants, their data, or biological material was used in this perspectives pieces. Therefore, ethics approval is not applicable in this case.

Consent to Participate Does not apply as no human subjects were involved.

Consent for Publication Does not apply as no human subjects were involved.

Conflicts of Interest The authors declare no competing interests.

\section{References}

1. Centers for Disease Control and Prevention. Cases in the U.S. 2020 2020-06-02 [cited 2020 June 03]; Available from: https:// www.cdc.gov/coronavirus/2019-ncov/cases-updates/cases-in-us. html.

2. Lousiana Department of Health. Coronavirus COVID-19. 2020 [cited 2020 June 03]. 
3. Bureau, U.S.C. U.S. Census Bureau QuickFacts: Louisiana. 2020 [cited 2020 June 03]; Available from: //www.census.gov/quick facts/LA.

4. Michigan Department of Health and Human Services,. Coronavirus - Michigan data. 2020 [cited 2020 June 03]; Available from: https://www.michigan.gov/coronavirus/0,9753,7-406-98163_ 98173---,00.html.

5. United States Census Bureau. U.S. Census Bureau QuickFacts: Michigan. 2020 [cited 2020 June 03]; Available from: //www. census.gov/quickfacts/fact/table/MI/RHI225218.

6. Kaiser Family Foundation. COVID-19 deaths by race/ethnicity. 2021 [cited 2021 September 14]; Available from: https://www.kff. org/other/state-indicator/covid-19-deaths-by-race-ethnicity/?curre ntTimeframe $=0 \&$ selectedDistributions $=$ black-percent-of-death s\&sortModel=\%7B \%22 colId \%22:\%22Location $\% 22, \% 22$ sort $\%$ 22:\%22asc\%22\%7D.

7. New York City Department of Health. COVID-19: data details on deaths - NYC Health. 2020 [cited 2020 June 03]; Available from: https://www1.nyc.gov/site/doh/covid/covid-19-data-deaths.page.

8. Sattar, N., I.B. McInnes, and J.J. McMurray, Obesity a risk factor for severe COVID-19 infection: multiple potential mechanisms. Circulation, 2020.

9. Dietz W, Santos-Burgoa C. Obesity and its implications for COVID-19 mortality. Obesity. 2020;28(6):1005-1005.

10. Simonnet, A., et al., High prevalence of obesity in severe acute respiratory syndrome coronavirus-2 (SARS-CoV-2) requiring invasive mechanical ventilation. Obesity, 2020.

11. Kalligeros, M., et al., Association of obesity with disease severity among patients with COVID-19. Obesity (Silver Spring, Md.), 2020.

12. Hales, C.M., et al., Prevalence of obesity and severe obesity among adults: United States, 2017-2018. 2020.

13. Ward ZJ, et al. Projected US state-level prevalence of adult obesity and severe obesity. N Engl J Med. 2019;381(25):2440-50.

14. Butryn ML, Webb V, Wadden TA. Behavioral treatment of obesity. Psychiatric Clinics. 2011;34(4):841-59.

15. Knowler WC, et al. Reduction in the incidence of type 2 diabetes with lifestyle intervention or metformin. N Engl J Med. 2002;346(6):393-403.

16. Wadden TA, et al. One-year weight losses in the Look AHEAD study: factors associated with success. Obesity. 2009; 17(4):713-22.

17. Svetkey L, et al. Effect of lifestyle modifications on blood pressure by race, sex, hypertension status, and age. J Hum Hypertens. 2005;19(1):21-31.

18. Haughton $\mathrm{CF}$, et al. Racial/ethnic representation in lifestyle weight loss intervention studies in the United States: a systematic review. Preventive Medicine Reports. 2018;9:131-7.

19. Goode RW, et al. African Americans in standard behavioral treatment for obesity, 2001-2015: what have we learned? West J Nurs Res. 2017;39(8):1045-69.

20. West DS, et al. Weight loss of black, white, and Hispanic men and women in the Diabetes Prevention Program. Obesity. 2008;16(6):1413-20.

21. Hollis JF, et al. Weight loss during the intensive intervention phase of the weight-loss maintenance trial. Am J Prev Med. 2008;35(2):118-26.

22. McClure ES, et al. Racial capitalism within public health-how occupational settings drive COVID-19 disparities. Am J Epidemiol. 2020;189(11):1244-53.

23. Laster Pirtle WN. Racial capitalism: a fundamental cause of novel coronavirus (COVID-19) pandemic inequities in the United States. Health Educ Behav. 2020;47(4):504-8.

24. Khanijahani, A. and L. Tomassoni, Socioeconomic and racial segregation and COVID-19: concentrated disadvantage and black concentration in association with COVID-19 deaths in the USA. Journal of racial and ethnic health disparities, 2021: p. 1-9.

25. Yang, T.-C., S.-w. Emily Choi, and F. Sun, COVID-19 cases in US counties: roles of racial/ethnic density and residential segregation. Ethnicity \& Health, 2021. 26(1): 11-21.

26. Bell CN, et al. Race disparities in cardiovascular disease risk factors within socioeconomic status strata. Ann Epidemiol. 2018;28(3):147-52.

27. Bell CN, Carr LTB. The role of weight perception in race differences in BMI among college graduate and non-college graduate women. Obesity. 2020;28(5):970-6.

28. Phelan JC, Link BG. Is racism a fundamental cause of inequalities in health? Ann Rev Sociol. 2015;41(41):311-30.

29. Bell, C.N., J. Kerr, and J.L. Young, Associations between obesity, obesogenic environments, and structural racism vary by countylevel racial composition. International Journal of Environmental Research and Public Health, 2019. 16(5).

30. Hicken MT, Lee H, Hing AK. The weight of racism: vigilance and racial inequalities in weight-related measures. Soc Sci Med. 2018;199:157-66.

31. Powell LR, Jesdale WM, Lemon SC. On edge: the impact of racerelated vigilance on obesity status in African-Americans. Obes Sci Pract. 2016;2(2):136-43.

32. Cozier Y, et al. Perceived racism and obesity incidence in African American women. Am J Epidemiol. 2013;177:S11-S11.

33. Cozier YC, et al. Racism, segregation, and risk of obesity in the black womens health study. Am J Epidemiol. 2014;179(7):875-83.

34. Coleman A, O'Neil J, Ferris AM. The mediation effect between everyday discrimination, gender role conflict, emotional eating, and obesity in African American fathers and sons. Psychology of Men \& Masculinity. 2019;20(2):182-93.

35. Johnson P, et al. Association of perceived racial discrimination with eating behaviors and obesity among participants of the SisterTalk Study. Journal of the National Black Nurses Association. 2012;23(1):34-40.

36. Thorpe RJ, et al. Association between discrimination and obesity in African-American men. Biodemography Soc Biol. 2017;63(3):253-61.

37. Cunningham TJ, et al. Racial/ethnic and gender differences in the association between self-reported experiences of racial/ethnic discrimination and inflammation in the CARDIA cohort of 4 US communities. Soc Sci Med. 2012;75(5):922-31.

38. Manns-James L. The weight of racism: obesity, racial discrimination and racial identity among African American college women in the US. Eur J Pub Health. 2018;28:179-80.

39. Pickett, S., et al., Understanding and effectively addressing disparities in obesity: a systematic review of the psychological determinants of emotional eating behaviours among Black women. Obesity Reviews, 2020. 21(6).

40. Edwards MB, Cunningham G. Examining the associations of perceived community racism with self-reported physical activity levels and health among older racial minority adults. J Phys Act Health. 2013;10(7):932-9.

41. Ray R. Black people don't exercise in my neighborhood: perceived racial composition and leisure-time physical activity among middle class blacks and whites. Soc Sci Res. 2017;66:42-57.

42. Longmire-Avital B, McQueen C. Exploring a relationship between race-related stress and emotional eating for collegiate Black American women. Women Health. 2019;59(3):240-51.

43. Gee GC, Ford CL. Structural racism and health inequities: old issues, new directions. Du Bois Review-Social Science Research on Race. 2011;8(1):115-32.

44. Bailey ZD, et al. Structural racism and health inequities in the USA: evidence and interventions. Lancet. 2017;389(10077):1453-63. 
45. White K, Borrell LN. Racial/ethnic residential segregation: framing the context of health risk and health disparities. Health Place. 2011;17(2):438-48.

46. Bower KM, et al. The intersection of neighborhood racial segregation, poverty, and urbanicity and its impact on food store availability in the United States. Prev Med. 2014;58(46):33-9.

47. Kwate NOA. Fried chicken and fresh apples: racial segregation as a fundamental cause of fast food density in black neighborhoods. Health Place. 2008;14(1):32-44.

48. Kwate NOA, et al. Inequality in obesigenic environments: fast food density in New York City. Health Place. 2009;15(1):364-73.

49. Bleich $\mathrm{SN}$, et al. Social context explains race disparities in obesity among women. J Epidemiol Community Health. 2010;64(5):465-9.

50. Bower KM, et al. Racial residential segregation and disparities in obesity among women. Journal of Urban Health-Bulletin of the New York Academy of Medicine. 2015;92(5):843-52.

51. Corral I, et al. Residential segregation, health behavior and overweight/obesity among a national sample of African American adults. J Health Psychol. 2012;17(3):371-8.

52. Do DP, et al. Neighborhood racial/ethnic segregation and BMI: a longitudinal analysis of the multi-ethnic study of atherosclerosis. Int J Obes. 2019;43(8):1601-10.

53. Goodman, M., et al., How segregation makes us fat: food behaviors and food environment as mediators of the relationship between residential segregation and individual body mass index. Frontiers in Public Health, 2018. 6.

54. Kershaw KN, Albrecht SS, Carnethon MR. Racial and ethnic residential segregation, the neighborhood socioeconomic environment, and obesity among Blacks and Mexican Americans. Am J Epidemiol. 2013;177(4):299-309.

55. Suglia SF, et al. Why the neighborhood social environment is critical in obesity prevention. Journal of Urban Health-Bulletin of the New York Academy of Medicine. 2016;93(1):206-12.

56. Thorpe RJ, et al. Explaining Racial disparities in obesity among men: does place matter? American Journal of Mens Health. 2015;9(6):464-72.

57. Armstrong-Brown J, et al. Redefining racial residential segregation and its association with physical activity among African Americans 50 years and older: a mixed methods approach. J Aging Phys Act. 2015;23(2):237-46.

58. Lopez R. Black-white residential segregation and physical activity. Ethn Dis. 2006;16(2):495-502.

59. Wilson-Frederick SM, et al. Examination of race disparities in physical inactivity among adults of similar social context. Ethn Dis. 2014;24(3):363-9.

60. Williams DR, Lawrence JA, Davis BA. Racism and health: evidence and needed research. Annu Rev Public Health. 2019;40(40):105-25.

61. Tung, E.L., et al., Police-recorded crime and disparities in obesity and blood pressure status in Chicago. Journal of the American Heart Association, 2018. 7(7).

62. Sewell, A.A., et al., Illness spillovers of lethal police violence: the significance of gendered marginalization. Ethnic and Racial Studies, 2020. in press.

63. Kumanyika, S., et al., Expanding the obesity research paradigm to reach African American communities. Preventing Chronic Disease, 2007. 4(4).

64. Alvidrez $\mathrm{J}$, et al. The national institute on minority health and health disparities research framework. Am J Public Health. 2019;109(S1):S16-20.

65. Barber, S., et al., COVID-19 in context: racism, segregation and racial inequities in Philadelphia. June 2020, Drexel University Urban Health Collaborative.
66. Poteat, T., et al., Understanding COVID-19 risks and vulnerabilities among Black communities in the America: the lethal force of syndemics. Annals of Epidemiology, 2020. 47.

67. Belanger, M.J., et al., Covid-19 and disparities in nutrition and obesity. New England Journal of Medicine.

68. Gray II, D.M., et al., COVID-19 and the other pandemic: populations made vulnerable by systemic inequity. Nature Reviews Gastroenterology \& Hepatology, 2020.

69. Yudell, M., et al., Taking race out of human genetics: engaging a century-long debate about the role of race in science. 2016, Science. p. 564-565.

70. Roberts D, Fatal invention : how science, politics, and big business re-create race in the twenty-first century. New York. UNITED STATES: The New Press; 2011.

71. Fitzgibbon ML, et al. Weight loss and African-American women: a systematic review of the behavioural weight loss intervention literature. Obes Rev. 2012;13(3):193-213.

72. Svetkey LP, et al. Predictors of long-term weight loss in adults with modest initial weight loss, by sex and race. Obesity. 2012;20(9):1820-8.

73. Jones, N., et al. 2020 Census illuminates racial and ethnic composition of the country. 2021 [cited 2021 September 20]; Available from: https://www.census.gov/library/stories/2021/08/improvedrace-ethnicity-measures-reveal-united-states-population-muchmore-multiracial.html.

74. Bray GA. Baseline characteristics of the randomised cohort from the Look AHEAD (Action for Health in Diabetes) study. Diab Vasc Dis Res. 2006;3(3):202-15.

75. Davis KK, et al. Racial differences in weight loss among adults in a behavioral weight loss intervention: role of diet and physical activity. J Phys Act Health. 2015;12(12):1558-66.

76. Blackman Carr LT, et al. Racial differences in weight loss mediated by engagement and behavior change. Ethn Dis. 2018;28(1):43.

77. Kochanek, K.D., et al., Deaths: final data for 2017. National Vital Statistics Reports. 2019, National Center for Health Statistics: Hyattsville, MD.

78. Priorities, C.o.B.a.P., SNAP helps millions of African Americans. 2017.

79. Bureau, U.S.C., $21.3 \%$ of U.S. participates in government assistance programs each month. 2015.

80. Burke MP, et al. Severity of household food insecurity and lifetime racial discrimination among African-American households in South Carolina. Ethn Health. 2018;23(3):276-92.

81. Gibson, A.N., et al., Struggling to breathe: COVID-19, protest and the LIS response. Equality, Diversity and Inclusion: An International Journal, 2020.

82. Kumanyika S. Overcoming Inequities in obesity: what don't we know that we need to know? Health Educ Behav. 2019;46(5):721-7.

83. Lungeanu A, Contractor NS. The effects of diversity and network ties on innovations: the emergence of a new scientific field. Am Behav Sci. 2015;59(5):548-64.

84. Allen WR, Jewell JO. A backward glance forward: past, present and future perspectives on historically Black colleges and universities. Rev High Educ. 2002;25(3):241-61.

85. Fiegener, M.K. and S.L. Proudfoot, Baccalaureate origins of UStrained S\&E doctorate recipients. Arlington, VA: National Science Foundation. Retrieved August, 2013. 27: p. 2020.

86. Gasman M, et al. HBCUs and the production of doctors. AIMS public health. 2017;4(6):579.

87. Himmelstein MS, Puhl RM, Quinn DM. Intersectionality: an understudied framework for addressing weight stigma. Am J Prev Med. 2017;53(4):421-31. 
88. Christopher $\mathrm{S}$, et al. Building and maintaining trust in a community-based participatory research partnership. Am J Public Health. 2008;98(8):1398-406.

89. Griffith DM. "Centering the margins": moving equity to the center of men's health research. Am J Mens Health. 2018;12(5):1317-27.

90. Ford CL, Airhihenbuwa CO. Critical race theory, race equity, and public health: toward antiracism praxis. Am J Public Health. 2010;100(S1):S30-5.

91. Deurenberg P, Yap M, Van Staveren WA. Body mass index and percent body fat: a meta analysis among different ethnic groups. Int J Obes. 1998;22(12):1164-71.

92. Calle EE, et al. Body-mass index and mortality in a prospective cohort of US adults. N Engl J Med. 1999;341(15):1097-105.

93. Stevens J, Cai J, Jones DW. The effect of decision rules on the choice of a body mass index cutoff for obesity: examples from African American and white women. Am J Clin Nutr. 2002;75(6):986-92.

94. Golden SD, Earp JAL. Social ecological approaches to individuals and their contexts: twenty years of health education \& behavior health promotion interventions. Health Educ Behav. 2012;39(3):364-72.

95. Stevens J, et al. Multilevel interventions targeting obesity: research recommendations for vulnerable populations. Am J Prev Med. 2017;52(1):115-24.

Publisher's Note Springer Nature remains neutral with regard to jurisdictional claims in published maps and institutional affiliations. 